\title{
South Carolina Groundwater Availability Assessment: 2017 Stakeholder Outreach and Engagement Results
}

\author{
Thomas Walker III ${ }^{1}$, Lori Dickes ${ }^{1}$, And Jeffery Allen ${ }^{1}$
}

AUTHORS: ${ }^{1}$ South Carolina Water Resources Center, Clemson University, 509 Westinghouse Road, Pendleton, SC 29670.

\begin{abstract}
An update of the State Water Plan is underway in South Carolina. The purpose of the State Water Plan is to develop a water resources policy for South Carolina. A significant portion of the State Water Plan update is to include stakeholders into the planning process. Clemson University continues to facilitate the stakeholder engagement components of the steps to an updated water plan. This research is pertinent to the Groundwater Availability Assessment phase of the State Water Planning process. Overall, stakeholders were interested in all identified groundwater areas of interest in South Carolina. Additionally, they intended to be involved in the entire stakeholder process for groundwater and became more informed on the Groundwater Availability Assessment. Stakeholders agreed that groundwater modeling provided useful information for users in the state and thought the Groundwater Availability Assessment was important for water resources management. Nuances in stakeholder types and registered or permitted users versus nonregistered or nonpermitted users provide important details beyond general results. Moving forward, there are some more mixed results of the stakeholder engagement meetings that are important for planning and decision-making. The groundwater assessment meeting results had general agreement about the appropriateness of the scope, but had less certainty than other questions. Stakeholders generally identified the need for the allocation of additional resources for the planning process. Additionally, mixed results highlight the differences surrounding perceptions of the need for statewide permitting of groundwater resources. This exploratory research is important to water management in South Carolina because it assesses buyin from those interested in or affected by water resource recommendations forthcoming at the end of the State Water Plan update.
\end{abstract}

\section{INTRODUCTION}

The purpose of the South Carolina Groundwater Availability Assessment is to update the 2010 groundwater flow model of the coastal plain (Gellici, 2017). Groundwater flow models are useful in predicting water-level declines, recharge rates, and impacts of groundwater withdrawals on aquifers, streamflows, and other users in the coastal plain (South Carolina Department of Natural Resources [SCDNR], 2015). Clemson University was contracted to facilitate the stakeholder engagement meetings as a part of the overall Groundwater Availability Assessment process. Because stakeholder involvement is a new approach to water planning in South Carolina, this study explored this approach taken in the Groundwater Availability Assessment pilot stakeholder engagement efforts.

The South Carolina Water Resources Center maintains an email distribution database with a third-party vendor for distribution of relevant water center news and events. The email distribution database is divided into several groups or data segments. Two population segments of the database were sent invitations to Phase 1 of the groundwater assessment meetings. The first group included 2,134 contacts, of which 494 invitations were opened (24.9\%), whereas the second group had 369 identified groundwater specific stakeholders, of which 123 were opened (36.9\%). This groundwaterspecific stakeholder list was put together, in part, by the Stakeholder Engagement Team (SET), after calling 224 stakeholders to determine contact information for additional stakeholder communication. The SET is composed of South Carolina Water Resources Center researchers contracted to facilitate water planning stakeholder meetings throughout the state. The South Carolina Groundwater Association was also contacted to distribute the meeting information to their distribution list comprised of about 81 members. This was distributed on November 14, 2017, to all Groundwater Association members by its staff. Social media provided additional outreach: Twitter, Facebook, and LinkedIn. 
Twitter posts had 2,269 impressions and 96 engagements. Facebook posts reached 675 viewers, with 14 post clicks and 9 reactions, comments, or shares; LinkedIn posts received approximately 90 views in the feed.

The Phase 1 Groundwater Availability Assessment stakeholder meetings were held on November 28, 2017, in North Charleston, South Carolina, and December 14, 2017, in West Columbia, South Carolina. The format of the meetings was as follows: (a) Clemson University welcome and introduction, (b) SCDNR water planning process update and groundwater methodology, (c) SCDNR Groundwater Availability Assessment, (d) U.S. Geological Survey (USGS) groundwater modeling, (e) Clemson University stakeholder engagement, (f) Clemson University concluding remarks, and (g) question-and-answer session with presenters facilitated by Clemson SET.

Although stakeholder engagement has become increasingly common (at times mandated) in the water planning process, there are different methodologies and approaches used in this type of process. Stakeholder involvement in the Groundwater Availability Assessment was desirable to move in a different direction from past topdown decision-making approaches in state water planning efforts. Stakeholder processes can range from informational to substantive stakeholder-driven decision-making (Cowie \& Borrett, 2005). This informative-advisory process combines disseminating information with gathering information on stakeholder perceptions. This research highlights the results of a hybrid approach to stakeholder engagement, one that accounts for potentially larger groups but still gathers individual information and feedback. Additionally, this approach adds applied research into stakeholder perceptions of groundwater modeling and groundwater-specific resource and policy issues in South Carolina from various perspectives: general stakeholder perceptions, perceptions based on stakeholder type, and registered or permitted user vs. nonregistered or nonpermitted user perceptions.

\section{LITERATURE REVIEW}

Collaborative resource management has become the new norm as water planning and policy has expanded beyond the purview of the state agencies charged with its management and regulation. As water planning and management have evolved in the United States, so has the collaborative nature of the water use sectors and stakeholders incorporated into the planning and decision-making process. Today, there is strong support for collaborative management as critical to successful decision-making processes and outcomes (Margerum \& Robinson, 2015). Collaborative management can be time consuming, as parties involved generally have framed water management differently depending on their use, which can increase the time needed to build consensus (Margerum \& Robinson, 2015).

Watershed partnerships with public involvement are an evolving area in water resource policy and management. Watershed partnerships go by many different names, such as councils, advisory groups, task forces, and committees (Sommarstrom in Born \& Genskow, 1999). Even if the process or management of these groups varies, in general, they are local or regional groups of stakeholders who meet to discuss and collaborate on relevant water policy and management at a watershed (or portion of a watershed) scale (Leach \& Pelky, 2001).

Groundwater modeling has become relatively standardized after decades of national and state modeling efforts. Literature has pointed to mixed results in participatory modeling including concerns about stakeholder involvement possibly degrading the scientific approach necessary to derive a quality product (Assata et al., 2008). Due to the well-defined and established methodology of assessing groundwater in South Carolina (Aucott et al., 1987; Campbell et al., 2017; Gellici, 2017) a fully participatory approach was not desirable for this phase of water planning. The question remains how the groundwater models will be used in future management and policy decision-making and enforcement.

Stakeholder engagement, therefore, is a complex issue. There have been a wide range of benefits documented as a result of stakeholder engagement efforts (Arnstein, 1969; Pretty, 2002; Ross et al., 2002; Rowe \& Frewer, 2005; International Association for Public Participation, 2014). The benefits include, but are not limited to, more effective decision-making by public and private parties around complex issues, more transparency and knowledge sharing by public organizations, enhanced understanding by government agencies of the policy impacts on communities and individuals, and improved knowledge of governmental processes for individuals and organizations in the community (Newig, 2007; Mackenzie et al., 2012). Overall stakeholder processes provide an opportunity to improve information transfer, increase knowledge for all parties, build capacity, and create networking opportunities around complex issues.

\section{METHODOLOGY}

Depending on project goals and objectives, as well as the time and resources available, stakeholder engagement can use different formats. For water management, stakeholders have a primary need for reliable, contemporary data on current groundwater availability, but also current data on withdrawals and use (Dilling et al., 2015). Given this, the process for these stakeholder engagement meetings followed more of an informational-advisory approach. Using Cowie and Borrett's (2005) model of decision-making, informational stakeholder engagement falls under a notification type of 
forum in which information is distributed and issues are explained; and advisory stakeholder engagement gathers perception feedback information.

In addition to information dissemination, real-time feedback was gathered by the Clemson SET using iClickers, and stakeholders were able to provide perception feedback and ask specific questions about the groundwater assessment project. iClickers are an information-collection tool used primarily in higher education to engage students in classroom settings. iClickers can also be used by researchers in other settings to provide anonymous feedback opportunities. This data collection technique was used to quantify stakeholder perceptions for more in-depth analysis in this process. The sampling performed for data collection and subsequent analysis followed a convenience sampling approach (Etikan et al., 2016).

The primary limitation of this engagement model is that, although it is efficient, it does not allow for building robust collaborative engagement. However, this model can be understood as a critical first step for complex issues that require building a foundation of information and networking from which to build a more collaborative and action oriented stakeholder processes.

\section{GROUNDWATER STAKEHOLDER ENGAGEMENT RESULTS}

The Clemson SET chose to use iClicker polling as the primary information and engagement approach in the groundwater phase of the planning process to allow for anonymity and data aggregation. This was the same approach chosen for the initial phase of the surface water stakeholder engagement meetings throughout the 8 river basins across South Carolina from 2015 to 2016. Surface water hydrology and groundwater hydrogeology were differentiated in the planning process. SCDNR decided the surface water planning process would follow a basin approach, whereas groundwater would follow a coastal plain approach, divided into inner coastal and outer coastal geographical areas. Stakeholder engagement meetings were held in each of the coastal geographical areas. The results are presented from 3 primary perspectives: (a) by stakeholder response to questions, (b) by stakeholder type in response to questions, and (c) by registered or permitted stakeholder category in response to questions.

Appendixes 1-3 are the groundwater data sets used to create figures for the results section. The 2 meeting data sets were combined and then analyzed to provide a broader analysis of state groundwater stakeholder perceptions because limited analysis could be performed using the 2 sets individually. There are limitations to the results because they are not generalizable to all groundwater stakeholders due to the sampling methodology, which was a convenience sampling approach rather than random sampling (Etikan et al., 2016). Additionally, a qualitative component might have provided more detailed responses. Sign-in sheets were examined for participant crossover to prevent double responses, and there was crossover in some governmental attendance but no crossover of meeting participants that provided feedback. The questions were asked to collect data on and document groundwater stakeholder demographics, groundwater interests, and stakeholder perceptions of the Groundwater Availability Assessment.

The first question for participants used a typology approach to categorize stakeholders (Appendix 1, Question 1). A typology of stakeholders can be important for policy and planning purposes. The typologies created for the groundwater assessment are broad due to the nature of the information collection tool. The types of stakeholders in water planning have many nuances that are difficult to capture with broad categories. However, categorization can be important to better understand perceptions and analyze feedback patterns of stakeholder responses based on type.

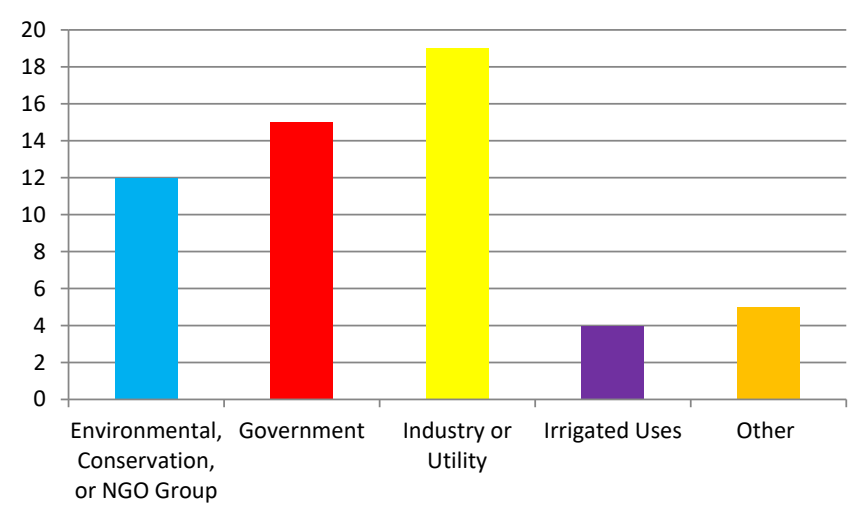

Figure 1. Organization type represented by stakeholder response. $\mathrm{NGO}=$ nongovernmental organization.

Industry and utility stakeholders had the strongest representation in the groundwater stakeholder meetings (Figure 1). Irrigated use stakeholders composed the least represented group in groundwater meetings. Government (local, state, federal, or higher education) and environmental, conservation, or nongovernmental organization (NGO) groups were also highly representative of the stakeholders in attendance at the groundwater meetings. Of interest is how irrigated use stakeholders are the least represented group but are identified as one of the main reasons water policy and legislation have been a point of emphasis in the state, largely due to perceptions of high and unregulated irrigation use (Jowers et al. v. South Carolina Department of Health and Environmental Control [SCDHEC], 2018). Utility, industry, and irrigation stakeholders are more likely to be registered or permitted users versus environmental and government stakeholders (Figure 2; Appendix 3, Question 1). 


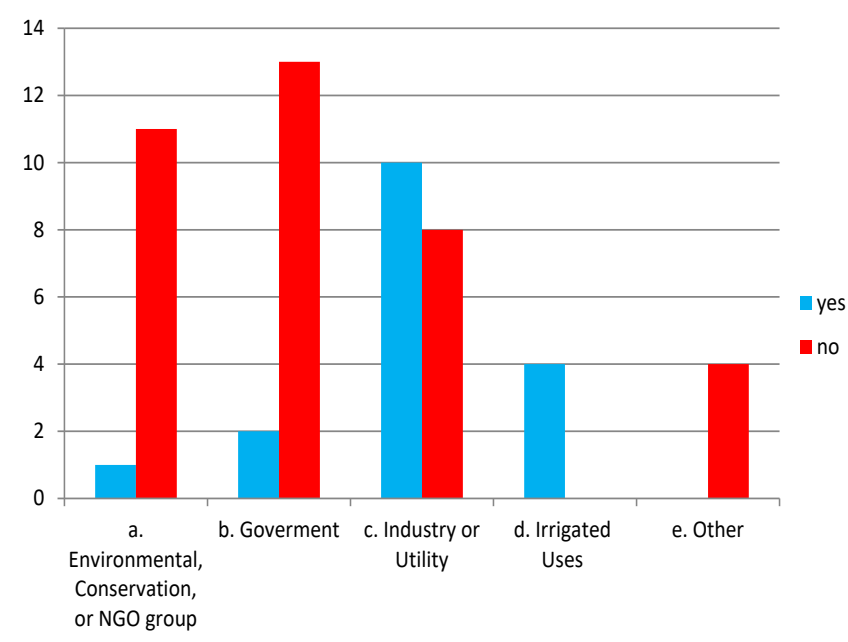

Figure 2. Organization type by registered or permitted stakeholder response. NGO = nongovernmental organization.

The next question directly asked if stakeholders were registered or permitted groundwater users (Appendix 1, Question 2). SCDHEC uses registration and permitting to account for groundwater use in the state of South Carolina. Registration is required if the user pumps 3 million gallons per month or more outside of the coastal plain; a notice of intent is required for groundwater pumping at or above the threshold in the coastal plain but not in a capacity use area. Permitting is required in capacity use areas of the state at or above the threshold (SCDHEC, 2018; Figure 3), and the state is currently in the process of designating a western South Carolina capacity use area in 2018. The majority

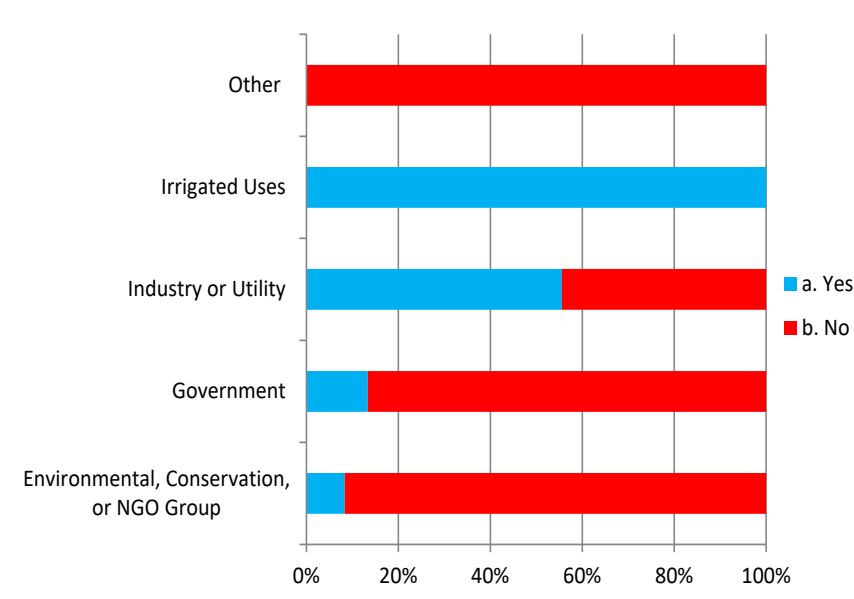

Figure 4. Registered or permitted response by stakeholder type. $\mathrm{NGO}=$ nongovernmental organization.

of stakeholders $(67.9 \%)$ were not registered or permitted groundwater users in the state of South Carolina. This unequal representation could lead to nonrepresentative results. Results based on this response were analyzed to examine this possibility and are presented in subsequent figures. Industry or utility and irrigated uses composed the majority of the registered or permitted stakeholders, whereas there was a smaller percentage of government and environmental, conservation, or NGO registered or permitted stakeholders represented (Figure 4; Appendix 2, Question 1). Many other, government, environmental, conservation, and NGO groups were not registered or permitted groundwater users, with the industry or utility sector having almost equal representation

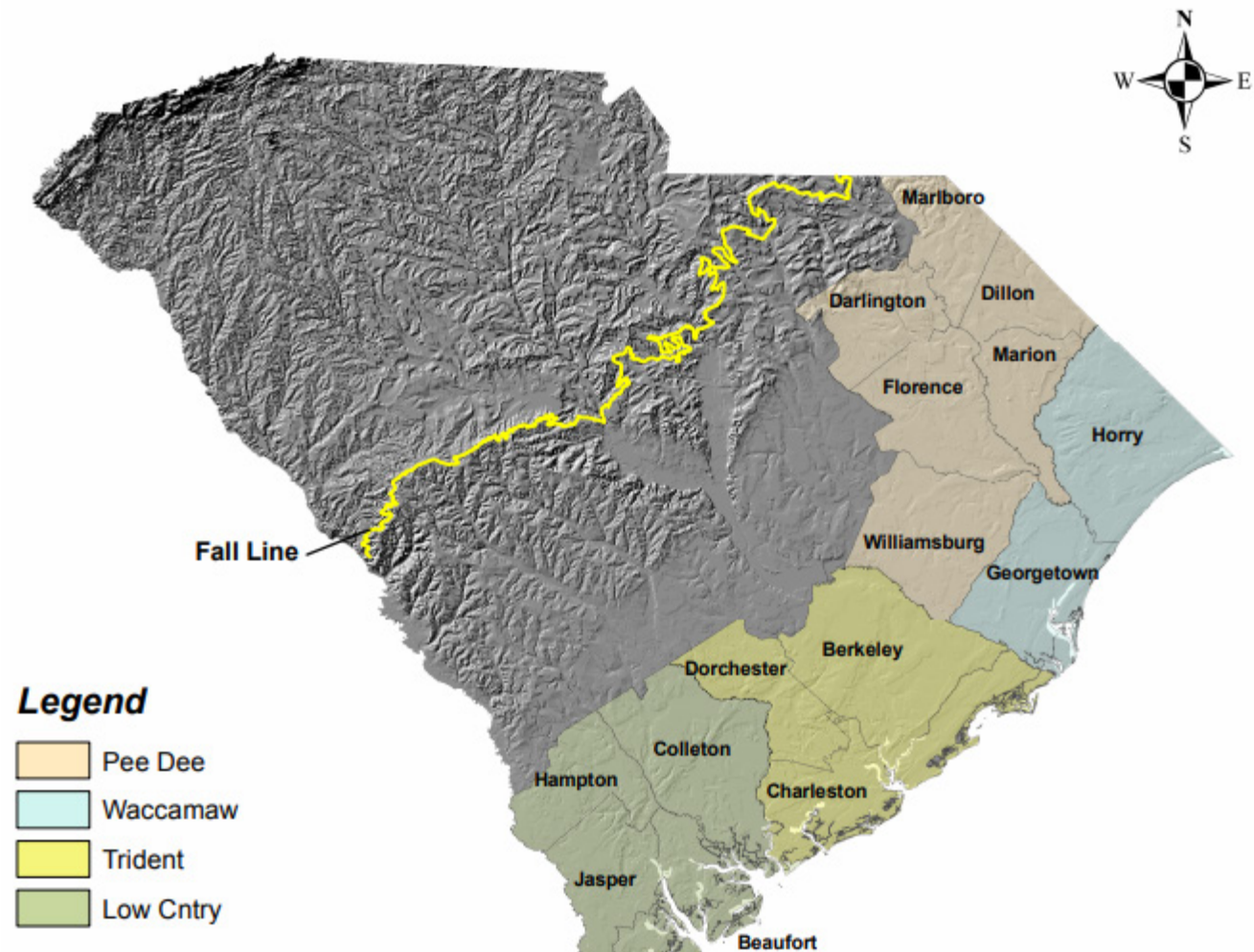

Figure 3. Current capacity use areas of South Carolina. (SCDHEC, 2018) 


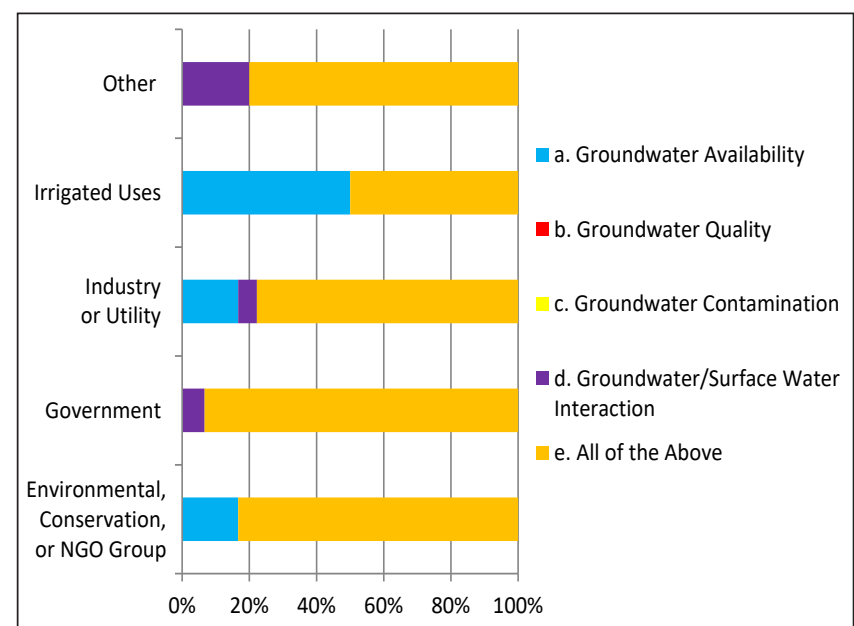

Figure 5. Stakeholder interests in groundwater by type. NGO = nongovernmental organization.

of registered or permitted users versus nonregistered or nonpermitted users.

The next question asked stakeholders to gauge their particular interest in groundwater (Appendix 1, Question 3). Although the purpose of the meetings was to inform stakeholders of the modeling efforts to assess the availability for current and future use in the state, very few were interested only in groundwater availability. Stakeholders were highly interested in all areas of groundwater issues in the state: availability, quality, contamination, and groundwater or surface water interaction (81.4\%). Groundwater quality focuses on dissolved chemicals and gases in the water from the area geography (water quality can be poor and not be contaminated). Groundwater contamination focuses on more manmade applied or leaked chemicals seeping into the groundwater. All of these (groundwater or surface water availability, groundwater quality, groundwater contamination, and groundwater or surface water interaction) had the highest response rate regardless of stakeholder type (Figure 5; Appendix 2, Question 2). The irrigated use stakeholder group was almost evenly split between interests in groundwater availability only or all of the topics, and some industry and utility and environmental, conservation, or NGO stakeholders also had interest in availability, in addition to all of these topics.

Some government, industry or utility, or other stakeholders had interest in groundwater or surface water interactions, as well as all other topics. The data revealed that registered or permitted stakeholders are generally most interested in all groundwater topics, but also showed an interest in just groundwater availability and groundwater or surface water interactions (Figure 6; Appendix 3, Question 2).

An important component of stakeholder engagement is classifying the geographical representation of participants. There were equal numbers of representatives from the Inner and Outer Coastal Plain areas of the state (Figure 7). The

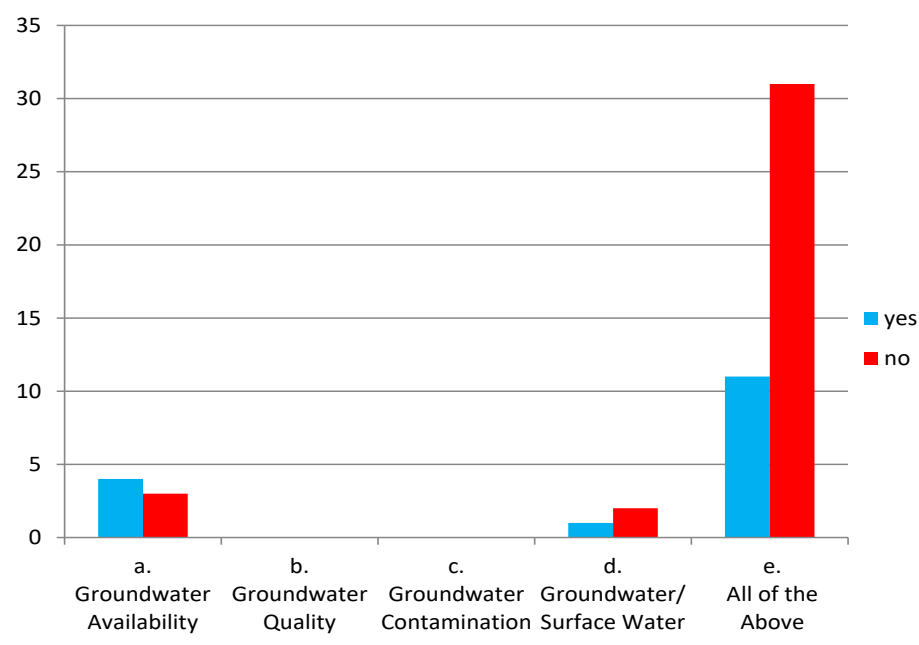

Figure 6. Groundwater interests by registered or permitted stakeholder response.

most highly represented response was that stakeholders embodied all groundwater areas of the state. The least represented area of the state is outside of the coastal plain, which includes the Piedmont area and is not a part of the Groundwater Availability Assessment effort. Industry or utility and government stakeholders had the highest response for representing all groundwater areas of the state (Figure 8; Appendix 2, Question 3). Irrigated uses and environmental, conservation, or NGO stakeholders largely represent the Inner Coastal Plain. The Inner Coastal Plain has been an area of interest at the regulatory level of the state. Currently, SCDHEC is assessing expanding designated capacity use areas to include parts of western South Carolina due to groundwater pumping, affecting recharge rates. The Outer Coastal Plain had more representation from government, industry or utility, and other stakeholder groups. Even though the Piedmont area of the state is not currently part of the groundwater availability assessment, some stakeholder represented this area at the groundwater stakeholder

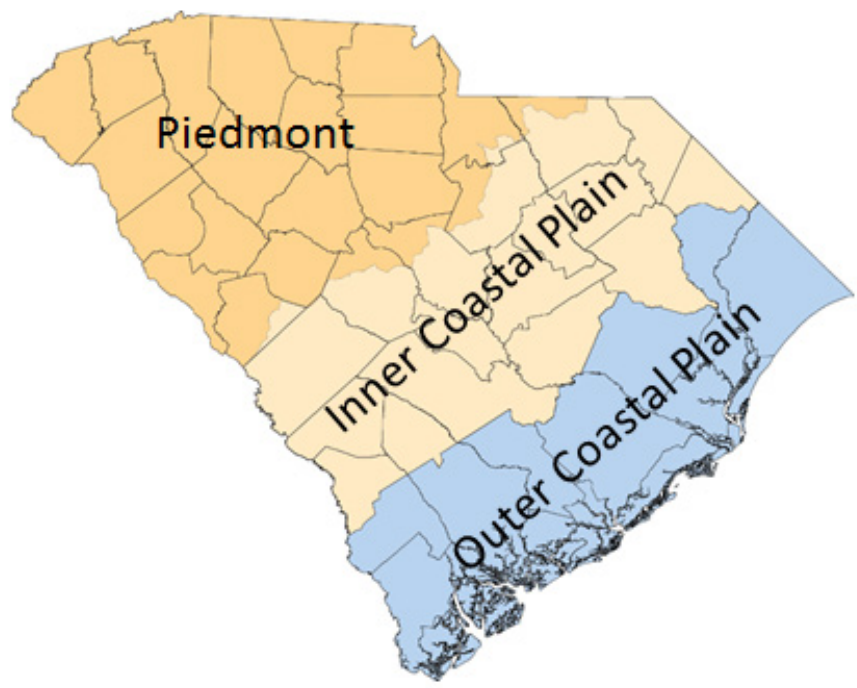

Figure 7. Geographical groundwater areas of South Carolina. 
meetings from industry or utility and other stakeholder groups. Nonregistered or nonpermitted users are more likely to respond that they represent the entire state than registered or permitted users, according to data collected. Industry or utility and government stakeholders had the highest response rates for representing all groundwater areas of the state (Figure 8; Appendix 2, Question 3), and government had the highest response of nonregistered or nonpermitted stakeholders (Figure 2; Appendix 3, Question 1).

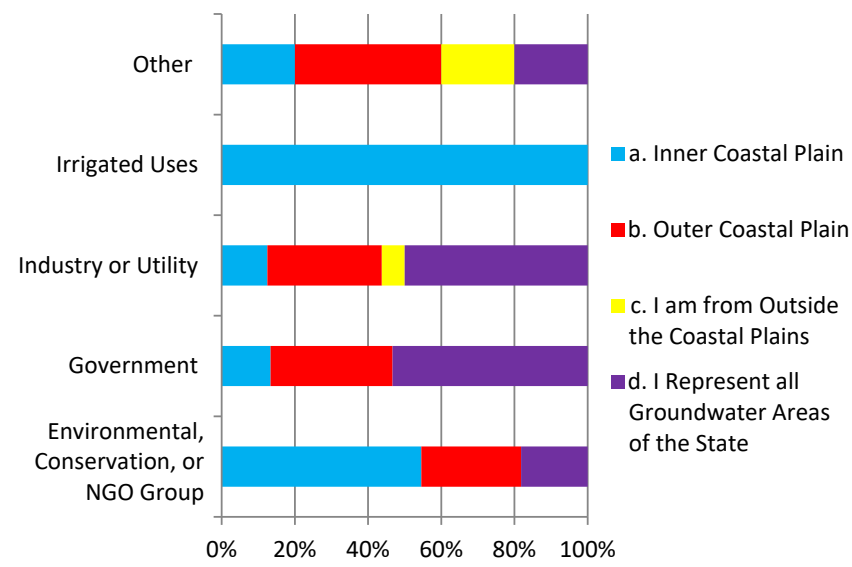

Figure 8. Geographical groundwater area represented by stakeholder type. NGO = nongovernmental organization.

A key objective of water planning and engagement is to support and encourage ongoing stakeholder involvement in these processes. The next question asked whether or not stakeholders intend to be involved in the entire groundwater stakeholder process (Appendix 1, Question 5).

Almost $75 \%$ of stakeholders who participated in the first round of groundwater engagement meetings responded that they will continue to participate in the entire process for the Groundwater Availability Assessment. Most stakeholders responded with interest in remaining engaged throughout the entire groundwater process in South Carolina (Figure 9; Appendix 2, Question 4). Additionally, there were some

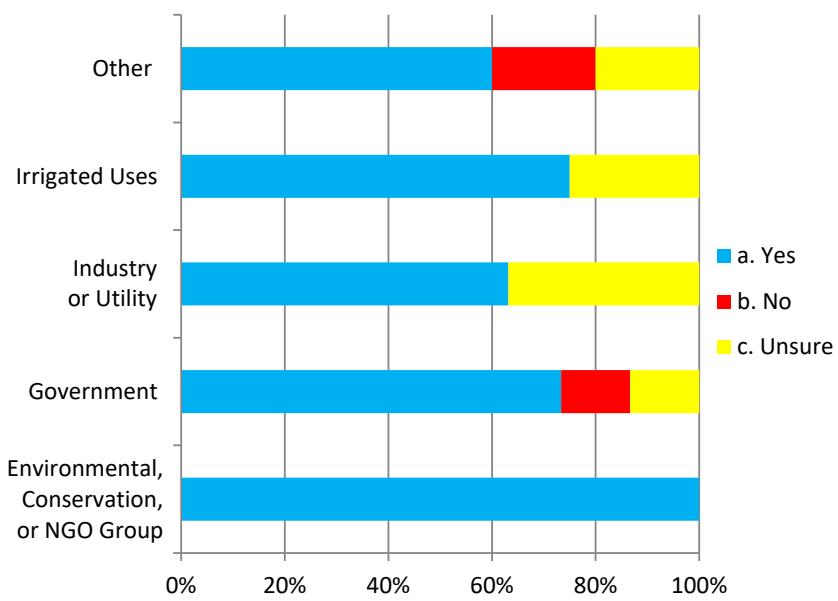

Figure 9. Intent to remain involved in the entire process for groundwater by stakeholder type. NGO = nongovernmental organization. groups who were unsure if they would remain involved in the participatory process. Other and government stakeholder types indicated that they would not continue to be engaged after the first round of meetings. Registered or permitted stakeholders are more likely to remain engaged in the entire process (Figure 10; Appendix 3, Question 4).

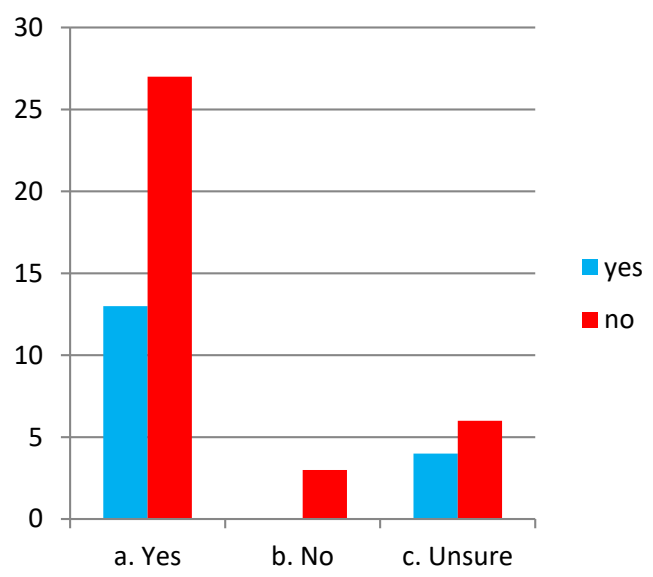

Figure 10. Intent to remain involved in the entire process for groundwater by registered or permitted stakeholder response.

The next several questions focused on the scope and resources of the groundwater availability and whether it was perceived as appropriate (Appendix 1, Questions 6 and 7). Stakeholders were asked these questions after presentations from SCDNR and USGS on the methodology, approach, and scope of the assessment. Approximately $80 \%$ of stakeholders strongly agreed or agreed that the scope of the Groundwater Availability Assessment was appropriate (Figure 11; Appendix 1, Question 6). Several groups did not know if the scope was appropriate, which could be due to a lack of familiarity with groundwater modeling at the state level or in general. There was some disagreement in industry or utility and environmental, conservation, or NGO groups and strong

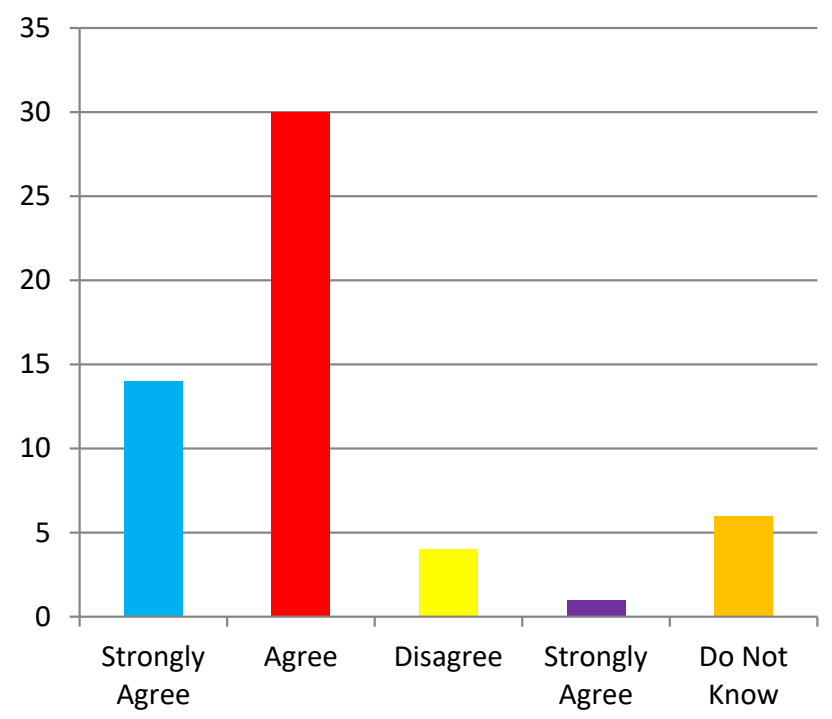

Figure 11. The scope of the Groundwater Availability Assessment is appropriate. 


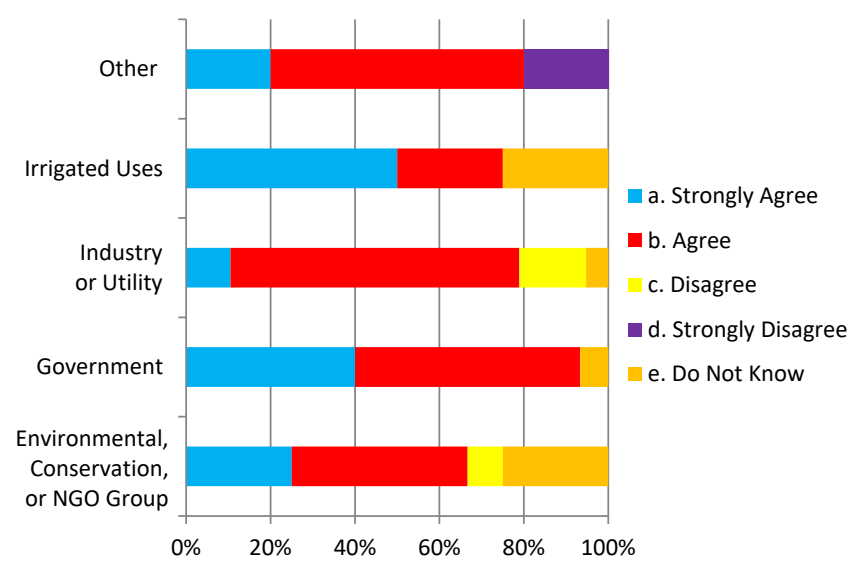

Figure 12. The scope of the Groundwater Availability Assessment is appropriate by stakeholder type. NGO = nongovernmental organization.

disagreement in the other stakeholder group (Figure 12; Appendix 2, Question 5). One of the more important aspects of stakeholder engagement for resource management and planning efforts is gauging approval of the scope of the project. Stakeholders generally agreed more than strongly agreed that the scope of the Groundwater Availability Assessment was appropriate regardless of registered or permitted stakeholder status. Both registered or permitted and nonregistered or nonpermitted stakeholders had some level of disagreement and some did not know if the scope was appropriate. These results are important for SC government and regulatory agencies as the state water planning process moves forward.

The next question focused more specifically on resources by addressing if stakeholders supported additional resource allocation for the state Groundwater Availability Assessment and water planning efforts (Appendix 1, Question 7). Support for additional resources for groundwater assessment and planning efforts received strong agreement. "Strongly agree" and "agree" received over $85 \%$ of the responses from stakeholders. This response is significant, but comes without discussion or information pertaining to the amount of resources currently being allocated to these efforts other than what was allocated for the surface water availability assessment efforts from the state legislature. The amount spent on the groundwater assessment was not disclosed in this round of stakeholder engagement. If this information was disclosed and stakeholders had a reference to gauge their response, their responses may be more nuanced than these results indicate. This would be especially important for those that responded "do not know." Additional reference points like other states' planning efforts and alternative modeling approaches were not discussed, nor was the amount of resources other states, especially neighboring states, have allocated to these efforts. Environmental, conservation, or NGO stakeholders and other had some disagreement in

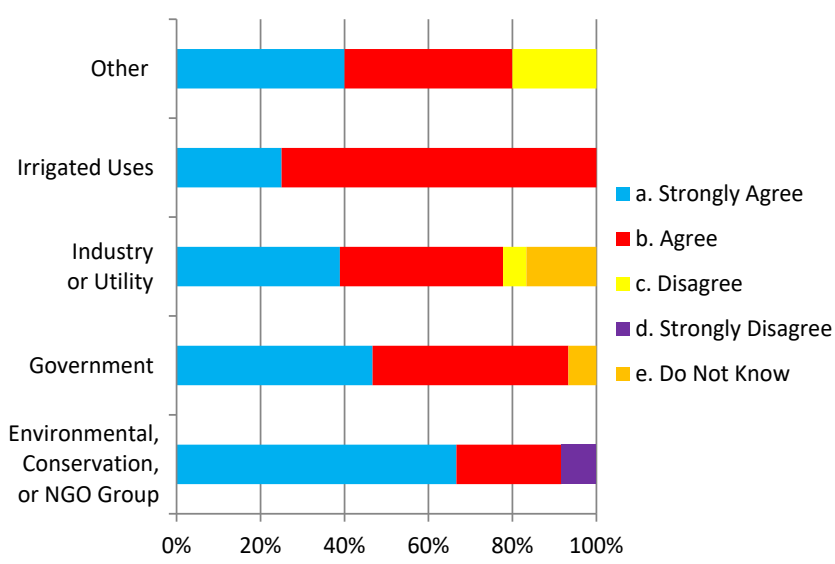

Figure 13. Support additional resources for the Groundwater Availability Assessment and planning efforts by stakeholder type. NGO = nongovernmental organization.

their support for additional resources for the Groundwater Availability Assessment (Figure 13; Appendix 2, Question 6).

There was general consensus among stakeholders regardless of registered or permitted user status in support of additional resources for groundwater assessment and planning efforts. There was a slight difference between nonregistered or nonpermitted stakeholders and registered or permitted stakeholders in strength of agreement (Figure 14; Appendix 3, Question 6). Nonregistered or nonpermitted users strongly agreed with the statement more so than registered or permitted users, who agreed more than strongly agreed with the statement.

The next question gauged the strength of the information content of the presentations (Appendix 1, Question 8). Stakeholders strongly agreed or agreed that the information communicated in the stakeholder engagement meetings was informative. These results reveal that the information

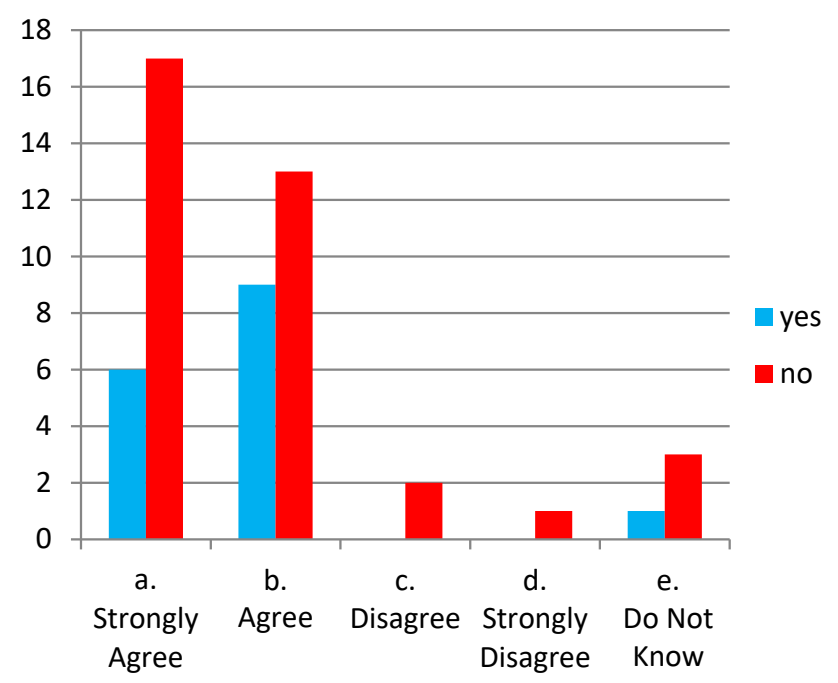

Figure 14. Support additional resources for the Groundwater Availability Assessment and planning efforts by registered or permitted stakeholder response. 


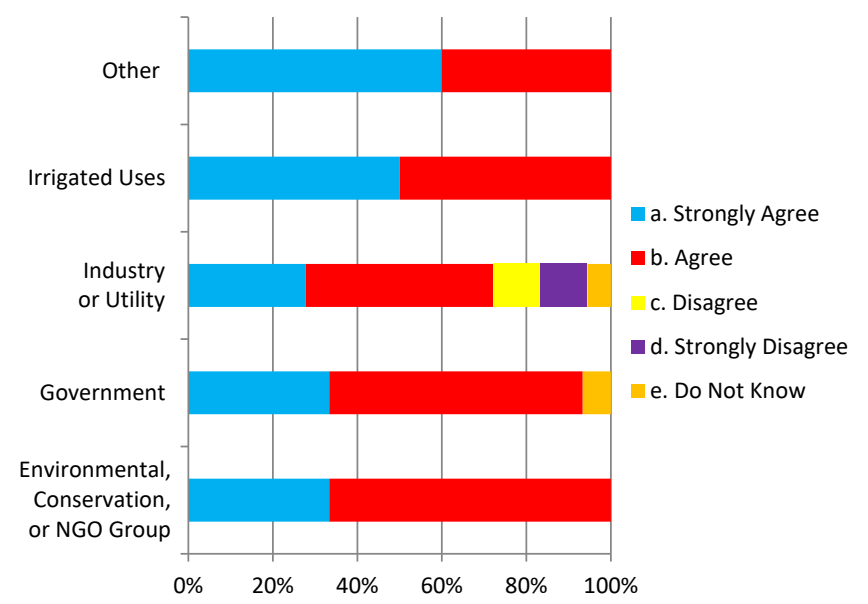

Figure 15. Stakeholders are more informed on the Groundwater Availability Assessment by stakeholder type. NGO = nongovernmental organization.

was presented in a manner that was understood by a diverse stakeholder group with various levels of expertise. The other stakeholder type strongly agreed more than the rest of the types that they were more informed on the Groundwater Availability Assessment from participating in the engagement meeting. All groups predominantly agreed to some extent that they felt more informed after the presentations from Clemson SET, SCDNR, and USGS. Industry or utility stakeholder groups had some disagreement and strong disagreement with the statement or did not know (Figure 15; Appendix 2, Question 7). Registered or permitted (81.25\%) or nonregistered or nonpermitted (91.66\%) stakeholders had high combined levels of "strongly agree" or "agree." Although we had some responses in the "disagree," "strongly disagree," or "do not know categories," those responses were very low.

The next question continued to inquire whether stakeholders were more informed after the Groundwater Availability Assessment presentations by asking if groundwater modeling provides useful information for groundwater users (Appendix 1, Question 9). In response, approximately $90 \%$ of stakeholders strongly agreed or agreed. The majority of stakeholder responses indicated that groundwater modeling efforts did provide useful information for groundwater users in the state. Industry or utility and environmental, conservation, or NGO both responded with some disagreement (Figure 16; Appendix 2, Question 8). Irrigated uses and other had some "do not know" responses, which could be reflective of the technical nature of groundwater modeling. There was little detectable difference between registered or permitted and nonregistered or nonpermitted stakeholders. However, there were a few responses from nonregistered or nonpermitted stakeholders that disagreed or strongly disagreed with the usefulness of this information.

As with many environmental planning efforts, one of the areas of ongoing concern for many stakeholders is how this information will be used and whether there is a

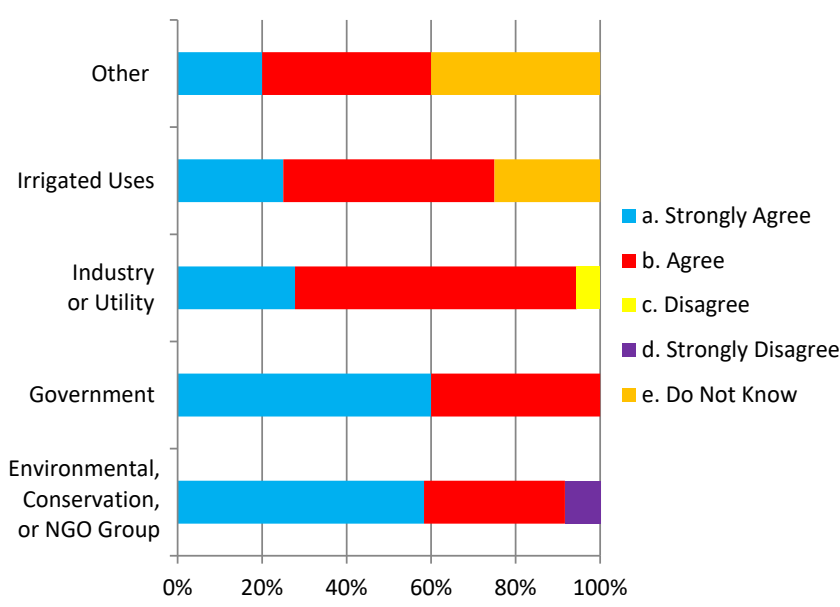

Figure 16. Groundwater modeling provides useful information for groundwater users in the state by stakeholder type. NGO = nongovernmental organization.

regulatory purpose for it. As such, stakeholders were asked whether or not they supported statewide groundwater withdrawal permitting. With the preliminary assessment and engagement for a new capacity use area in western South Carolina underway, groundwater registration and permitting policy has been receiving increased attention in the state. This question gauged stakeholders' general support for statewide groundwater permitting. Overall, the highest response from stakeholders was that they strongly support statewide groundwater permitting (54.7\%). When looking at the overall distribution of responses, approximately $45 \%$ were not strongly in favor of statewide groundwater withdrawal permitting but, instead, responded that they did not support statewide groundwater permitting (3.7\%), supported only regional permitting where groundwater problems exist (24.5\%), or were not sure (16.9\%; Figure 17; Appendix 1, Question 10).

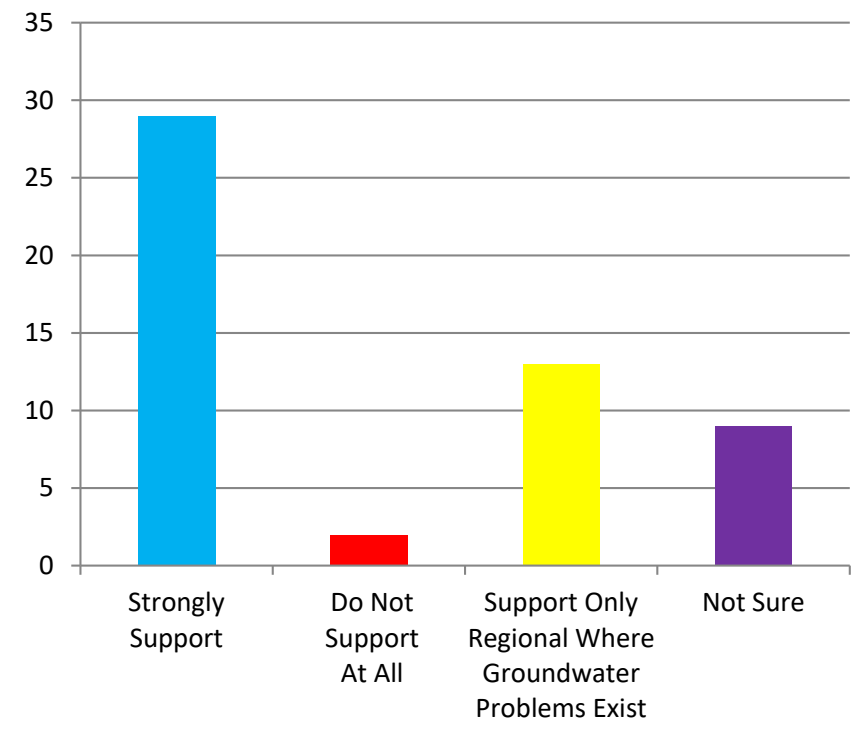

Figure 17. Stakeholder support for statewide groundwater withdrawal permitting. 


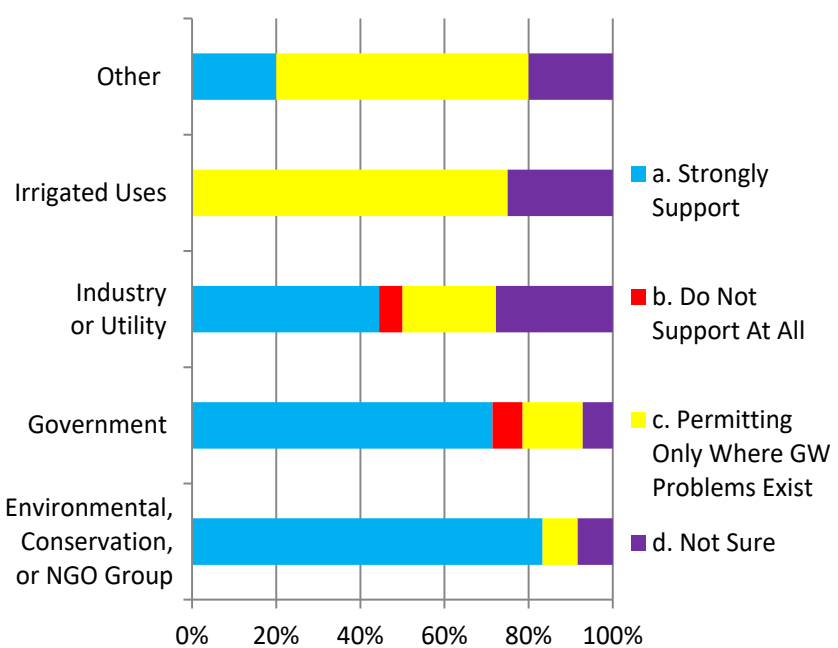

Figure 18. Stakeholder support for statewide groundwater withdrawal permitting by stakeholder type. NGO = nongovernmental organization.

Groundwater permitting across the state was most highly supported by environmental, conservation, or NGO groups, followed by government stakeholders (Figure 18; Appendix 2, Question 9). Industry and utility were more evenly distributed in their support. Irrigated uses and other stakeholders were more supportive of permitting only where identified groundwater problems exist or were uncertain. The stakeholder responses for support of various permitting options for the state were different for registered or permitted users and nonregistered or nonpermitted users. Registered or permitted users were well distributed among strongly supporting statewide groundwater permitting, supporting groundwater permitting only in regions where problems exist, and not sure if they support any of the available options (Figure 19; Appendix 3, Question 9). Nonregistered or nonpermitted stakeholders had higher response rates in

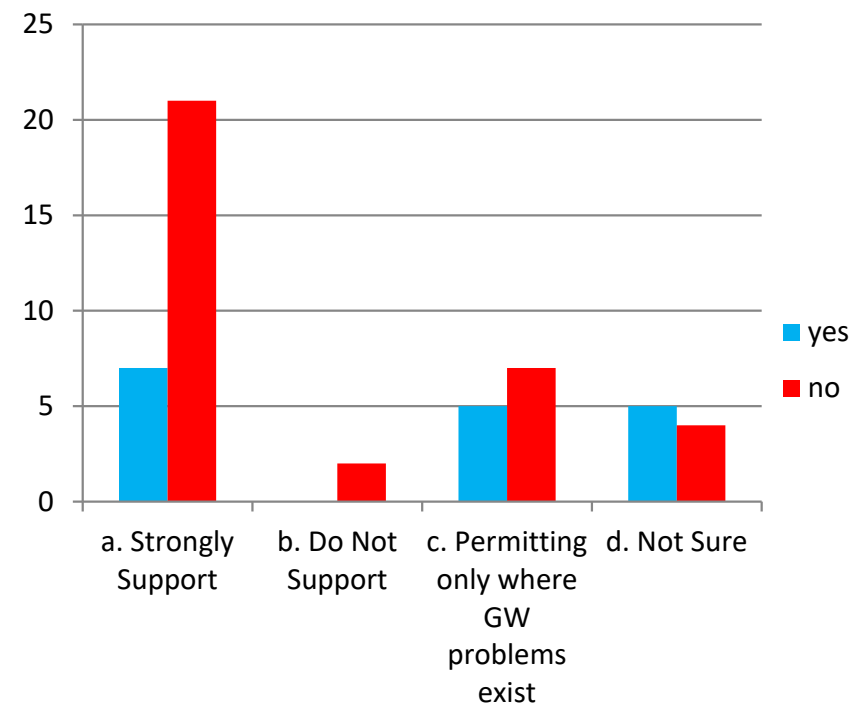

Figure 19. Stakeholder support for statewide groundwater withdrawal permitting by registered or permitted stakeholder response. strongly supporting statewide groundwater permitting, but also had responses in not supporting statewide groundwater permitting, supporting groundwater permitting only in regions where problems exist, and not being sure if they support any of the available options. A high degree of variability in these responses is cause for reflection for policymakers. If any permitting efforts were proposed, a higher level of engagement and information sharing would be important. Currently, the state is undertaking a preliminary assessment for expanding designated capacity use areas registration and permitting, which, based on this question, provides an opportunity for the state to build capacity around this issue with appropriate investment in public engagement and information sharing.

The final question asked stakeholders how important they felt the Groundwater Availability Assessment is for water resources management in the state of South Carolina (Appendix 1, Question 11). The Groundwater Availability Assessment is a critical component for South Carolina to plan and ensure long-term access to the state's groundwater resources. Stakeholders highly agreed that this effort was either "very important" or "somewhat important" ( $81.4 \%$ and $14.8 \%$, respectively). Therefore, the Groundwater Availability Assessment is important to all stakeholder groups. Irrigated use and environmental, conservation, and NGO stakeholders responded that the assessment was "very important" at a higher percentage than other stakeholder groups (Figure 20; Appendix 2, Question 10). Both registered or permitted and nonregistered or nonpermitted stakeholders responded similarly in that groundwater modeling efforts for the state were "very important" or "important." Very few stakeholders came away from the engagement meetings not knowing if groundwater modeling was important for state water resource planning.

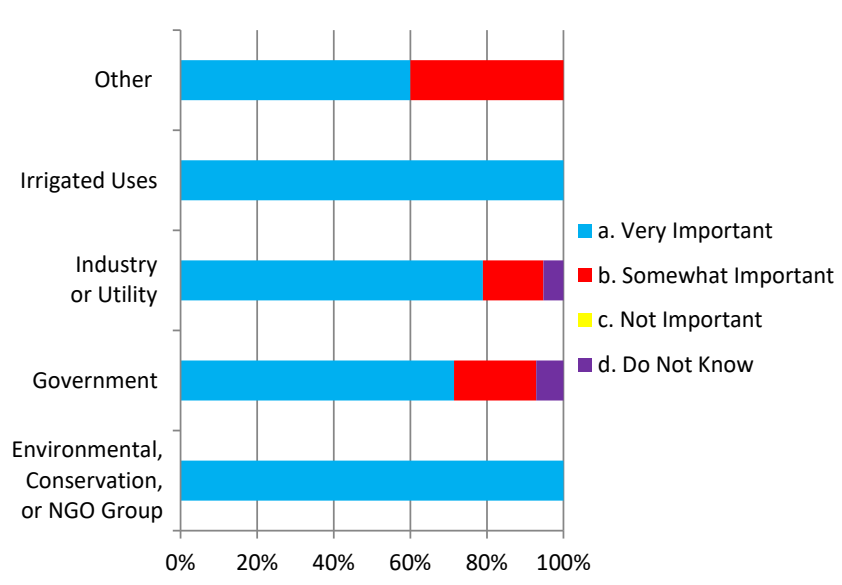

Figure 20. Importance of the Groundwater Availability Assessment by stakeholder type. NGO = nongovernmental organization. 


\section{DISCUSSION}

This is the first time the state of South Carolina has engaged in statewide water modeling and stakeholder engagement efforts around state water resource issues. As such, it is important to begin to characterize the nature of these types of efforts across the state. For example, who participates in these efforts and what is the nature of participation from different groups and organizations across the state? As well, it is increasingly important for policymakers and regulators to understand stakeholder perceptions around environmental and natural resource issues for effective management and use of these resources. Stakeholder methodology around issues that affect an entire region or state underscore the importance of broad and varied participation across groups. As such, these initial stakeholder meetings will allow the SET to begin to understand the potential gaps or weaknesses in participation. One such gap in participation could be agricultural interests. Agricultural water use and community perceptions of this use have been a point of contention in some areas of the state in that it is perceived that the agricultural industry is being treated differently than other water use sectors (Jowers et al. v. SCDHEC, 2018). Getting agricultural stakeholders engaged in the water planning process could perhaps reframe those perceptions if they were present to engage in meaningful dialogue with other stakeholders. Ensuring equity in participation is an important goal for this type of stakeholder effort. To ensure robust stakeholder efforts, they should incorporate methods of engagement, meeting style, and promotion that facilitate and support the broadest participation. This research reveals strong participation from key groups, with some responses highlighting areas of future research and stronger engagement needed in the future.

For example, several questions highlight areas of uncertainty where ongoing stakeholder involvement is important. The method of stakeholder involvement used here is valid and useful but is largely focused on providing information and understanding, as opposed to actionoriented processes. Results reveal there are several areas in which stakeholders have some degree of uncertainty in this process. Three areas specifically provide areas of consideration for policymakers in the state: (a) appropriateness of modeling efforts, (b) allocation of necessary resources, and (c) nature of potential permitting around groundwater resources.

All of these areas had enough stakeholders who indicated disagreement or uncertainty that opportunities exist for further information sharing or more in-depth engagement around these issues. For highly technical issues, like water modeling, ensuring that stakeholders have enough information, without creating more confusion or misunderstanding, is critical.

Similarly, any policy issue that may impact permitting and regulation necessitates a more robust stakeholder process.
Without additional engagement efforts, policymakers may find themselves in more contentious and challenging situations with different stakeholder groups as they attempt to implement policy changes. For example, models of stakeholder engagement that provide opportunities for different scenarios and dialogue around when additional permitting may be important could be useful in the future. As these results highlight, not all regulation is perceived negatively. However, additional information and dialogue from diverse groups would be critical to ensuring new regulation was perceived more positively.

Models of stakeholder engagement vary with a range of types of engagement and related outcomes (Cowie \& Borrett, 2005). For the type of engagement initiated in this research, the outcomes were achieved. Results overwhelmingly reveal that individuals felt informed, had a greater understanding of the process, and were potentially primed for additional engagement. As the state moves forward developing advisory basins, more in-depth stakeholder efforts will be important. As noted, this is especially true around issues of permitting and regulations. In particular, stakeholder efforts that create conversation, commitment, and collaborative planning are important. Taking lessons from community-based resource management to increase knowledge and support for collaborative management of the state's water resources is a valuable approach for all stakeholders and one that could provide long-term benefits for the state and its natural resources.

\section{LITERATURE CITED}

Arnstein SR. 1969. A ladder of citizen participation. J Am Inst Plann. 35(2):216-224.

Assata H, van Beek E, Borden C, Gijsbers P, Jolma A, Kaden S, Kaltofen M, Labadie JW, Loucks DP, Quinn NWT, et al. 2008. Generic simulation models for facilitating stakeholder involvement in water resources planning and management: a comparison, evaluation, and identification of future needs. Dev. Integr. Environ. Assess. 3:229-246.

Aucott WR, Davis ME, Speiran GK. 1987. Geohydrologic framework of the coastal plain aquifers of South Carolina (Water-Resources Investigations Report 85-4271).

Columbia (SC): U.S. Geological Survey.

Born SM, Genskow KD. 1999. Exploring the watershed approach: critical dimensions of state-local partnerships: the Four Corners Watershed Innovators Initiative final report. Portland (OR): River Network.

Campbell B, Cherry G, Fine J, Butler A, Gellici J. 2017. South Carolina coastal plain groundwater availability model-an update. Presented at: Groundwater Availability Assessment-Meeting 1, November 28, 2017, North Charleston, SC.

Cowie GM, Borrett SR. 2005. Institutional perspectives on participation and information in water management. Environ Model Softw. 20:469-483. 
Dilling L, Lackstrom K, Haywood B, Dow K, Lemos MC, Berggren J, Kalafatis S. 2015. What stakeholder needs tell us about enabling adaptive capacity: the intersection of context and information provision across regions in the United States. Weather Clim Soc. 7(1):5-17.

Etikan I, Musa SA, Alkassim RS. 2016. Comparison of convenience sampling and purposive sampling. Am J Theor Appl Stat. 5(1):1-4. doi:10.11648/j. ajtas.20160501.11.

Gellici J. 2017. The hydrogeologic framework developed for the South Carolina coastal plain groundwater flow model. Presented at: Groundwater Availability AssessmentMeeting 1, November 28, 2017, North Charleston, SC. International Association for Public Participation. (2014). IAP2 Spectrum of Public Participation. https://cdn. ymaws.com/www.iap2.org/resource/resmgr/foundations course/IAP2 P2 Spectrum FINAL.pdf

Jowers JJ Sr, Anastos AJ, Williamson B, Ruhlman M, Ruhlman A v. SCDHEC. South Carolina Supreme Court. Appellate Case No. 2016-000428. 2018.

Leach WD, Pelkey NW. 2001. Making watershed partnerships work: a review of the empirical literature. J Water Resour Plan Manag. 127(6)378-385.

Mackenzie J, Poh-Ling T, Hoverman S, Baldwin C. 2012. The value and limitations of participatory action research methodology. J Hydrol. 474, 11-21.

Margerum RD, Robinson CJ. 2015. Collaborative partnerships and the challenges for sustainable water management. Curr Opin Environ Sustain. 12:53-58.

Newig J. 2007. Does public participation in environmental decisions lead to improved environmental quality? Towards an analytical framework. Int J Sustain Commun. 1(1):51-71.

Pretty J. 2002. Agri-culture: reconnecting people, land, and nature. London (UK): Earthscan.

Ross H, Buchy M, Proctor W. 2002. Laying down the ladder: a typology of public participation in Australian natural resource management. Aust J Environ Manag. 9(4):205217.

Rowe G, Frewer LJ. 2005. A typology of public engagement mechanisms. Sci Technol Hum Values. 30(2):251-290.

South Carolina Department of Health and Environmental Control (SCDHEC). 2018. Groundwater use and reporting in capacity use areas-overview. Web.

South Carolina Department of Natural Resources (SCDNR). 2015. South Carolina surface-water quantity models: step 2 groundwater flow models. Presentation. 


\section{APPENDIX 1:}

\section{Groundwater Stakeholder Engagement Responses}

\begin{tabular}{lll}
\hline Question & $n$ & $\%$ \\
\hline
\end{tabular}

1. Which organization type do you represent? $n=55$

Environmental, conservation, or nongovernmental organization

Government

Industry or utility

Irrigated uses

Other

2. Are you a registered/permitted water user? $n=53$

$$
\begin{array}{lll}
\text { Yes } & 17 & 0.32075 \\
\text { No } & 36 & 0.67925
\end{array}
$$

3. My interests are mainly in __ . $n=54$

Groundwater availability

Groundwater quality

Groundwater contamination

Groundwater/surface water

interaction

All of the above

4. Which groundwater area do you represent? $n=51$

Inner coastal plain

Outer coastal plain

I am from outside the coastal plains

I represent all groundwater areas of the state

5. Do you intend to be involved in the entire stakeholder process for groundwater? $n=55$

Yes

No

Unsure

6. In my opinion, the scope of the Groundwater Availability Assessment is appropriate. $n=55$

Strongly agree
Agree
Disagree
Strongly agree
Do not know

$12 \quad 0.21818$

$15 \quad 0.27273$

$19 \quad 0.34545$

$4 \quad 0.07273$

$5 \quad 0.09091$

$\begin{array}{ll}7 & 0.12963 \\ 0 & 0 \\ 0 & 0 \\ 3 & 0.05556 \\ & \\ 44 & 0.81481\end{array}$

$15 \quad 0.29412$

$15 \quad 0.29412$

20.03922

$19 \quad 0.37255$

$$
19.37255
$$

$\begin{array}{cl}41 & 0.74545 \\ 3 & 0.05455 \\ 11 & 0.2\end{array}$

\begin{tabular}{lcc}
\hline Question & $\boldsymbol{n}$ & $\%$ \\
\hline 7. I support additional resources for the & & \\
Groundwater Availability Assessment & & \\
and planning efforts. $n=54$ & & \\
$\quad$ Strongly agree & 25 & 0.46296 \\
$\quad$ Agree & 22 & 0.40741 \\
Disagree & 2 & 0.03704 \\
$\quad$ Strongly agree & 1 & 0.01852 \\
$\quad$ Do not know & 4 & 0.07407
\end{tabular}

8. Would you agree that you are now more informed on the Groundwater Availability Assessment? $n=54$

$\begin{array}{lcc}\text { Strongly agree } & 19 & 0.35185 \\ \text { Agree } & 29 & 0.53704 \\ \text { Disagree } & 2 & 0.03704 \\ \text { Strongly agree } & 2 & 0.03704 \\ \text { Do not know } & 2 & 0.03704\end{array}$

9. Groundwater modeling provides useful information for groundwater users in the state. $n=54$

$\begin{array}{lcc}\text { Strongly agree } & 23 & 0.42593 \\ \text { Agree } & 26 & 0.48148 \\ \text { Disagree } & 1 & 0.01852 \\ \text { Strongly agree } & 1 & 0.01852 \\ \text { Do not know } & 3 & 0.05556\end{array}$

10. Do you support statewide groundwater withdrawal permitting? $n=53$

Strongly support

$29 \quad 0.54717$

Do not support at all

Support only regional where

$2 \quad 0.03774$

groundwater problems exist

$13 \quad 0.24528$

Not sure

$9 \quad 0.16981$

11. How important do you feel the Groundwater Availability Assessment is for water resources management? $n=54$

Very important

$44 \quad 0.81481$

Somewhat important

$8 \quad 0.14815$

Not important

$0 \quad 0$

Do not know

$2 \quad 0.03704$ 


\section{ApPendix 2:}

Groundwater Stakeholder Engagement Responses by Organization Type

\begin{tabular}{|c|c|c|c|c|c|}
\hline Question & $\begin{array}{c}\text { Environmental, } \\
\text { Conservation, or } \\
\text { Nongovernmental } \\
\text { Group } \\
\end{array}$ & Government & $\begin{array}{c}\text { Industry or } \\
\text { Utility }\end{array}$ & $\begin{array}{l}\text { Irrigated } \\
\text { Uses }\end{array}$ & Other \\
\hline \multicolumn{6}{|l|}{$\begin{array}{l}\text { 1. Are you a registered/permitted water user? } \\
n=53\end{array}$} \\
\hline Yes & 1 & 2 & 10 & 4 & 0 \\
\hline No & 11 & 13 & 8 & 0 & 4 \\
\hline \multicolumn{6}{|l|}{ 2. My interests are mainly in __. $n=54$} \\
\hline Groundwater availability & 2 & 0 & 3 & 2 & 0 \\
\hline Groundwater quality & 0 & 0 & 0 & 0 & 0 \\
\hline Groundwater contamination & 0 & 0 & 0 & 0 & 0 \\
\hline Groundwater/surface water interaction & 0 & 1 & 1 & 0 & 1 \\
\hline All of the above & 10 & 14 & 14 & 2 & 4 \\
\hline \multicolumn{6}{|l|}{$\begin{array}{l}\text { 3. Which groundwater area do you represent? } \\
n=51\end{array}$} \\
\hline Inner coastal plain & 6 & 2 & 2 & 4 & 1 \\
\hline Outer coastal plain & 3 & 5 & 5 & 0 & 2 \\
\hline I am from outside the coastal plains & 0 & 0 & 1 & 0 & 1 \\
\hline I represent all groundwater areas of the state & 2 & 8 & 8 & 0 & 1 \\
\hline \multicolumn{6}{|l|}{$\begin{array}{l}\text { 4. Do you intend to be involved in the entire } \\
\text { stakeholder process for groundwater? } n=55\end{array}$} \\
\hline Yes & 12 & 11 & 12 & 3 & 3 \\
\hline No & 0 & 2 & 0 & 0 & 1 \\
\hline Unsure & 0 & 2 & 7 & 1 & 1 \\
\hline \multicolumn{6}{|l|}{$\begin{array}{l}\text { 5. In my opinion, the scope of the Groundwater } \\
\text { Availability Assessment is appropriate. } n=55\end{array}$} \\
\hline Strongly agree & 3 & 6 & 2 & 2 & 1 \\
\hline Agree & 5 & 8 & 13 & 1 & 3 \\
\hline Disagree & 1 & 0 & 3 & 0 & 0 \\
\hline Strongly disagree & 0 & 0 & 0 & 0 & 1 \\
\hline Do not know & 3 & 1 & 1 & 1 & 0 \\
\hline \multicolumn{6}{|l|}{$\begin{array}{l}\text { 6. I support additional resources for the } \\
\text { Groundwater Availability Assessment and } \\
\text { planning efforts. } n=54\end{array}$} \\
\hline Strongly agree & 4 & 5 & 5 & 2 & 3 \\
\hline Agree & 8 & 9 & 8 & 2 & 2 \\
\hline Disagree & 0 & 0 & 2 & 0 & 0 \\
\hline Strongly disagree & 0 & 0 & 2 & 0 & 0 \\
\hline Do not know & 0 & 1 & 1 & 0 & 0 \\
\hline
\end{tabular}


Environmental,

Conservation, or

Nongovernmental

Question

Group

Government $\begin{gathered}\text { Industry or } \\ \text { Utility }\end{gathered} \quad \begin{gathered}\text { Irrigated } \\ \text { Uses }\end{gathered}$ Other

7. Would you agree that you are now more informed on the Groundwater Availability

Assessment? $n=54$

Strongly agree

Agree

Disagree

Strongly disagree

Do not know

8. Groundwater modeling provides useful information for groundwater users in the state. $n=54$

7

4

0

1

0

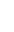

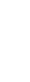

(n)

$\begin{array}{cc}12 & 10 \\ 0 & 3 \\ 0 & 0 \\ 0 & 1\end{array}$

Strongly agree

Agree

Disagree

Strongly disagree

Do not know

9. Do you support statewide groundwater withdrawal permitting? $n=53$

Strongly support

Do not support at all

Permitting only where groundwater

problems exist

Not sure

0. How important do you feel the

Groundwater Availability Assessment is for water resources management? $n=54$

Very important

Somewhat important
10

0

1

1
1
7

4

0

1

0

Not important

Do not know

9
6
0
0

$\begin{array}{ccc}5 & 1 & 1 \\ 12 & 2 & 2 \\ 1 & 0 & 0 \\ 0 & 0 & 0 \\ 0 & 1 & 2\end{array}$

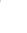


APPENDIX 3:

Groundwater Stakeholder Response by Registered/Permitted User Response

\begin{tabular}{lcc}
\hline Question & Yes & No \\
\hline $\begin{array}{l}\text { 1. Which organization type do you } \\
\text { represent? } n=53\end{array}$ & & \\
$\quad$ Environmental, conservation, or & 1 & 11 \\
$\quad$ nongovernmental organization & & \\
$\quad$ Government & 2 & 13 \\
$\quad$ Industry or utility & 10 & 8 \\
$\quad$ Irrigated uses & 4 & 0 \\
$\quad$ Other & 0 & 4 \\
2. My interests are mainly in & & \\
$n=52$ & 4 & 3 \\
$\quad$ Groundwater availability & 0 & 0 \\
$\quad$ Groundwater quality & 0 & 0 \\
$\quad$ Groundwater contamination & 1 & 2 \\
$\quad$ Groundwater/surface water & & \\
$\quad$ interactions & 11 & 31 \\
$\quad$ All of the above & & \\
3. Which groundwater area do you \\
represent? $n=49$
\end{tabular}

\begin{tabular}{lcc}
\hline Question & Yes & No \\
\hline 6. I support additional resources for the & & \\
Groundwater Availability Assessment & & \\
and planning efforts. $n=52$ & & \\
$\quad$ Strongly agree & 6 & 17 \\
Agree & 9 & 13 \\
Disagree & 0 & 2 \\
Strongly disagree & 0 & 1 \\
Do not know & 1 & 3
\end{tabular}

7. Would you agree that you are now more informed on the Groundwater Availability Assessment? $n=52$

$\begin{array}{lcc}\text { Strongly agree } & 6 & 12 \\ \text { Agree } & 7 & 21 \\ \text { Disagree } & 1 & 1 \\ \text { Strongly disagree } & 2 & 0 \\ \text { Do not know } & 0 & 2\end{array}$

8. Groundwater modeling provides useful information for groundwater users in the state. $n=52$

$\begin{array}{lcc}\text { Strongly agree } & 7 & 16 \\ \text { Agree } & 9 & 16 \\ \text { Disagree } & 0 & 1 \\ \text { Strongly disagree } & 0 & 1 \\ \text { Do not know } & 1 & 1\end{array}$

9. Do you support statewide groundwater withdrawal permitting? $n=51$

$\begin{array}{lcc}\text { Strongly support } & 7 & 21 \\ \text { Do not support } & 0 & 2 \\ \text { Permitting only where groundwater } & 5 & 7 \\ \text { problems exist } & & \\ \text { Not sure } & 5 & 4\end{array}$

10. How important do you feel the Groundwater Availability Assessment is for water resources management? $n=52$

$\begin{array}{lcc}\text { Very important } & 16 & 27 \\ \text { Somewhat important } & 0 & 7 \\ \text { Not important } & 0 & 0 \\ \text { Do not know } & 1 & 1\end{array}$

